\title{
Per-capita public expenditures and population size: a non-parametric analysis using French data
}

\author{
Robert Breunig • Yvon Rocaboy
}

Received: 26 November 2007 / Accepted: 18 March 2008 / Published online: 9 April 2008

(C) Springer Science+Business Media, LLC. 2008

\begin{abstract}
Based on the median voter model, we specify a flexible general framework of the effect of municipality size on per-capita public expenditures. Previous literature has recognized that municipality size should have a non-linear effect on the quality of public goods provision and to this end different papers have applied a range of alternative parametric specifications. Using a very large sample of French "communes" we are able to estimate the effect of municipality size semi-parametrically. In contrast with the parametric specifications, we find evidence of the U-shaped relationship between per-capita public expenditures and population which is predicted by theory.
\end{abstract}

Keywords Local Public Economics · Semi-parametric econometrics · Congestion

JEL Classification $\mathrm{C} 14 \cdot \mathrm{H} 4 \cdot \mathrm{H} 7 \cdot \mathrm{R} 51$

\section{Introduction}

Since the seminal papers by Borcherding and Deacon (1972), and Bergstrom and Goodman (1973), local fiscal choice is often considered as resulting from the maximization program of a median, or decisive, voter. Local population size is a parameter that appears in the decisive voter's maximization problem through the tax price which she faces. As suggested by theory, the impact of increasing population on tax price depends on the relative magnitude of two opposing effects: the congestion costs and the tax-sharing advantages, the former raises the tax price, while the latter pushes it down when population increases. These two effects

R. Breunig

Research School of Social Sciences, H C Coombs Bldg, The Australian National University, Canberra, ACT 0200, Australia

e-mail: robert.breunig@anu.edu.au

Y. Rocaboy $(\bowtie)$

Université de Rennes 1, CREM-CNRS, Faculté des sciences économiques, 7 Place Hoche,

35065 Rennes, France

e-mail: yvon.rocaboy@univ-rennes1.fr 
are the foundations of the theory of clubs established by Buchanan (1965). As a result, population size has an impact on the demand for local public goods and subsequently on local public expenditures.

Many papers have been devoted to analyzing econometrically the effect of population size on local public expenditure. These papers are somehow related to the measurement of congestion in the provision of local public goods (e.g., Oates 1988; Gonzalez et al. 1993; Hudson and Jones 2005). Most of them found no evidence of economies of scale or economies of sharing in the provision of local public goods, suggesting that publicly provided goods have the same properties as private goods. These studies call into question the public goods rationale for government (e.g., Holcombe and Sobel 1995). A notable exception can be found in McMillan et al. (1981) who found a higher degree of publicness in smaller municipalities than in larger ones. ${ }^{1}$

In this paper we re-examine this question using a semi-parametric econometric method on a sample of more than 36,000 French municipalities (communes). We compare our results to the parametric studies and demonstrate that none of the typically estimated parametric models fit the data particularly well. While parametric specifications fail to show scale economies in the provision of local public goods, our semi-parametric specification does uncover scale economies for smaller municipalities. We show that per capita local public expenditures decrease with population until a threshold is reached, and then increase above that point. The paper is organized as follows. Section 2 presents the theoretical link between population size and per capita public expenditure within the decisive voter framework. Section 3 describes both the parametric and semi-parametric methods used in the paper. Section 4 gives a brief description of the data, Sect. 5 presents the results, and Sect. 6 concludes.

\section{Population size and public expenditure}

In this section we analyze the effect of increasing population size on per capita public expenditure. As in most of the studies following Borcherding and Deacon (1972) on the provision of public goods, we assume that per capita public expenditure is the result of a decisive voter's maximization program. The budgetary constraint of the decisive voter $i$ is written as follows

$$
y_{i}=x_{i}+t b_{i},
$$

where $y_{i}$ is voter income, $x_{i}$ is her private consumption, $t$ is the tax rate of the jurisdiction and $b_{i}$ the tax base of the voter.

The budgetary constraint of the jurisdiction is given by

$$
t B+S=p Z,
$$

where $B$ denotes the total tax base, $S$ the lump-sum revenues granted by higher levels of government, and $p$ is the price per unit of public services $Z$.

The important element of this literature comes from the nature of local public goods which are generally regarded as congestible. This is modeled through the use of a congestion function

$$
q=q(Z, N),
$$

\footnotetext{
${ }^{1}$ For a comprehensive presentation of this literature, see Reiter and Weichenrieder (1997).
} 
where $q$ denotes the quality of local public services and $N$ is the number of users. Theoretically, we expect that $\partial q / \partial Z>0$ and $\partial q / \partial N<0$. This congestion function describes the fact that for a given quantity of local public services, $Z$, there is a tradeoff between the number of users, $N$, and the quality of services, $q$, enjoyed by each. For example, the transportation system within a jurisdiction may deliver rapid access to important points if the number of users is small but the quality of the transportation system will deteriorate as the population increases and roads become congested. This congestion effect is typical of impure public goods. ${ }^{2}$

Most studies assume that $q$ and $Z$ are proportional: ${ }^{3}$

$$
q=g(N) Z
$$

with $g^{\prime}<0$.

Combining (1), (2) and (4) provides

$$
y_{i}+\frac{b_{i}}{B} S=x_{i}+c q,
$$

where

$$
c=p \frac{b_{i}}{B} \frac{1}{g(N)}
$$

denotes the tax price of the decisive voter per unit of quality of local public services. Increasing the population size of a jurisdiction has two opposite effects on the voter tax price. First it raises the total fiscal base $B$ of the jurisdiction. Public expenditures are then shared by more taxpayers which reduces the individual tax price per unit of public good $Z$. Second it increases congestion in the consumption of $Z$, which raises the individual tax price per unit of quality. The total impact depends on the relative magnitude of these two effects.

Denoting the per capita fiscal base $b=\frac{B}{N}$, the marginal impact of increasing population size $N$ on individual tax price $c$ is given by the following expression:

$$
\frac{\partial c}{\partial N}=-\frac{c}{N}(\eta+1)
$$

where $\eta=\frac{\partial q}{\partial N} \frac{N}{q}=\frac{d g}{d N} \frac{N}{g}$ denotes the congestion elasticity. It measures the percentage change in the quality of services for a one percent increase in population size, while maintaining the total quantity of public goods constant.

If $\eta=0$, there is no congestion, public goods are considered as pure in the sense of Samuelson and the tax price $c$ is a decreasing function of the population size. If $\eta<0$, some degree of congestion is caused by additional users. In the case of $\eta<-1$, public goods are highly congestible, and congestion costs outweigh tax sharing advantages implying that an increase in population size results in a tax price increase. If $-1<\eta<0$ the advantage of a larger tax base outweighs the congestion cost and the tax price drops as population size grows.

We can easily show that the impact of increasing the population of a jurisdiction on its per capita public expenditure depends not only on the value of $\eta$ through the tax price but

\footnotetext{
${ }^{2}$ In this paper we do not deal with excludability issues but focus on crowding effects. This makes the difference between impure public goods and club goods (Cornes and Sandler 1996).

${ }^{3}$ See Reiter and Weichenrieder (1999) for a discussion of this assumption.
} 
also on the price elasticity of the decisive voter's demand for local public good quality. Multiplying both sides of (4) by the price, $p$, per unit of public good gives:

$$
p q=g(N) p Z \text {. }
$$

Denoting by $q=q(c(N), \cdot)$ the demand function of the decisive voter for local public good quality and by $e=\frac{p Z}{N}$ public expenditure per person, (8) may be re-written as,

$$
e=\frac{p q(c(N), \cdot)}{N g(N)} \text {. }
$$

Public expenditure per capita depends, amongst other factors, on the voter tax price $c$ which itself depends on population $N$ as suggested by (7). Using (9) we compute the marginal change in per capita public expenditure due to an increase in population size,

$$
\frac{\partial e}{\partial N}=-\frac{e}{N}(\alpha+1)(\eta+1)
$$

where $\alpha=\frac{\partial q}{\partial c} \frac{c}{q}$ denotes the price elasticity of voter demand for public good quality. If public services are highly congestible $(\eta<-1)$, increasing the population leads to a rise in the individual tax price (7). The effect on per capita public expenditure depends on the price elasticity. If the demand for public goods is very elastic $(\alpha<-1)$, the tax price increase leads to a sharp decrease in the demand for public goods, and then to a drop in public expenditure per person. If demand is inelastic $(\alpha>-1)$, the rise in individual tax price is accompanied by an increase in per capita public expenditure. If public service quality is slightly congestion-sensitive $(0>\eta>-1)$, the individual tax price decreases when population size rises, which yields a rise (if $\alpha<-1$ ) or a diminution (if $\alpha>-1$ ) in per capita public expenditure. Finally, if public goods are pure (there is no congestion, $\eta=0$ ), a population increase leads to a decrease in voter tax price. This is due to public expenditure being shared by a larger number of taxpayers. In this case, only tax-sharing advantages are at stake. The overall effect on public expenditures depends only on price elasticity.

This analysis depends crucially upon the assumption that the price per unit of public good is not a function of population size. In our econometric analysis below, we attempt to control for factors which might be related to both population size and unit costs of public good production.

\section{Specification of the public expenditure function}

As stated above, per capita public expenditure depends (among other parameters) on the relative magnitude of congestion costs and tax sharing advantages. In previous studies the properties of the congestion function have been assessed through the parameter estimates of ad hoc model specifications. We first consider these and then propose a semi-parametric approach to investigate the effect of increasing population size on per capita local public expenditure.

\subsection{The parametric specification}

The parametric specifications of the per capita public expenditure function are based on different formulations of the congestion elasticity $\eta$. The literature generally proposes three 
functional forms: ${ }^{4}$ The Borcherding-Deacon formulation which corresponds to a constant elasticity $\eta=\gamma_{0}$, the Camaraderie formulation where the congestion elasticity is an affine function of the population: $\eta=\gamma_{0}+\gamma_{1} N$, and the Flexible formulation which approximates the congestion elasticity function with a third order polynomial: $\eta=\gamma_{0}+\gamma_{1} N+2 \gamma_{2} N^{2}+$ $3 \gamma_{3} N^{3}$. Plugging these different formulations into (10) and integrating to get per capita expenditure functions, we have:

Borcherding-Deacon:

$$
\ln (e)=w^{\prime} \Phi-\Omega_{0} \ln (N)+\varepsilon,
$$

where $w^{\prime}$ is a vector of exogenous variables, $\Phi$ a vector of parameters to be estimated, and $\Omega_{0}=(\alpha+1)\left(\gamma_{0}+1\right)$.

Camaraderie:

$$
\ln (e)=w^{\prime} \Phi-\Omega_{0} \ln (N)-\Omega_{1} N+\varepsilon
$$

where $\Omega_{1}=(\alpha+1) \gamma_{1}$.

Flexible:

$$
\ln (e)=w^{\prime} \Phi-\Omega_{0} \ln (N)-\Omega_{1} N-\Omega_{2} N^{2}-\Omega_{3} N^{3}+\varepsilon,
$$

where $\Omega_{2}=(\alpha+1) \gamma_{2}$, and $\Omega_{3}=(\alpha+1) \gamma_{3}$. Each of these nests the preceding specifications; see the Appendix for details.

\subsection{The semi-parametric specification}

We propose using a method which allows the effect of $N$ on $e$ to vary in an unspecified, non-parametric way. The effect on $e$ of the other variables is estimated parametrically. The local public expenditure function can be written as follows:

$$
\ln (e)=w^{\prime} \Phi+m(\ln (N))+\varepsilon .
$$

We use $\ln (N)$ rather than $N$ as the former is nearly normally distributed. (See Figs. 2 and 3.)

We will use the following approach. Consider

$$
E[\ln (e) \mid \ln (N)]=E\left[w^{\prime} \mid \ln (N)\right] \Phi+m(\ln (N))
$$

and therefore

$$
\ln (e)-E[\ln (e) \mid \ln (N)]=w^{\prime} \Phi-E\left[w^{\prime} \mid \ln (N)\right] \Phi+\varepsilon .
$$

We estimate $E[\ln (e) \mid \ln (N)]$ and $E\left[w^{\prime} \mid \ln (N)\right]$ by a set of bivariate, non-parametric (local linear) regressions, and $\Phi$ by a linear regression of $\ln (e)-\widehat{E}[\ln (e) \mid \ln (N)]$ on $w^{\prime}-\widehat{E}\left[w^{\prime} \mid \ln (N)\right]$.

We then have

$$
m(\ln (N))=E[\ln (e) \mid \ln (N)]-E\left[w^{\prime} \mid \ln (N)\right] \Phi
$$

and an estimate

$$
\widehat{m}(\ln (N))=\widehat{E}[\ln (e) \mid \ln (N)]-\widehat{E}\left[w^{\prime} \mid \ln (N)\right] \widehat{\Phi} .
$$

\footnotetext{
${ }^{4}$ The Appendix gives a short presentation of the specifications of the congestion function which lead to the different formulations of the congestion elasticity. See Guengant et al. (2002) for a more detailed discussion on this point.
} 
In the econometric analysis, the explanatory variable vector $w$ is mostly composed of the per person variables of the decisive voter program, which are those generally used in the empirical literature on local public spending (e.g., Turnbull and Mitias 1999). These include $\frac{b_{i}}{b}$, grants per capita received from the central government $s$, and the average (per-person) total household income of the municipality $y .{ }^{5}$ The inclusion of the last two variables follows the "asymmetric income-grant" form of the median voter model. Voter income and voter share of central government grants are allowed to have different effects on local public expenditure (see Turnbull and Mitias 1995). The asymmetry may arise from bureaucracy or fiscal illusion. This asymmetric specification has been more popular in the literature than the symmetric restriction.

One important caveat to this model is that the marginal production cost of local public goods may be different across municipalities. Firstly, differences in marginal cost could be explained by the wage policy of the municipalities. In the French case, however, the latter do not have any degree of freedom since wage rates are chosen at the national level and must be uniformly applied all over the country. Secondly, the spatial allocation of endowments in geographical resources is unequal and may be correlated with population size. We attempt to deal with this source of disparity by introducing two geographical variables: surface area (denoted SUR) and average altitude (denoted ALT) of the local territory. The use of surface controls for population density and captures the unequal distribution of land across municipalities. An important number of small rural communities face the problem of declining population whilst the fixed cost of infrastructure does not diminish in proportion-surface will also help to capture this reality. The relative rigidity in the provision of some public services (like roads) proves to be a budgetary burden for some municipalities. The introduction of altitude captures the higher cost of infrastructure due to topography and climate for a non negligible number of mountain municipalities in France. In our econometric implementation of the model, we assume that there are no other economies or diseconomies of scale aside from those captured by surface area and altitude in the production of public goods. Although this assumption is ubiquitous in the literature, it will be important to keep it in mind when interpreting the results.

Finally we use a dummy variable, $D_{g}=1$ if the municipality belongs to a group of cooperating municipalities (see below) and $D_{g}=0$ otherwise. The vector of explicative variables $w^{\prime}$ is then as $w^{\prime}=\left(1, \ln (\mathrm{SUR}), \ln (\mathrm{ALT}), \ln \left(\frac{b_{i}}{b}\right), \ln (s), \ln \left(y_{i}\right), D_{g}\right)$ and $\Phi=\left(\Phi_{0}, \Phi_{1}, \Phi_{2}, \Phi_{3}, \Phi_{4}, \Phi_{5}, \Phi_{6}\right)^{\prime}$.

\section{Data}

We begin with a short description of the French local public sector. There are three levels of local government in France. The regions are the upper tier of government and the most recently established one, with 22 regions created in 1986. The members of the intermediate tier are called départements (numbering 100) while the communes form the lower tier. There are 36,565 communes, providing an impressive specificity of the French local public sector. Average commune population is 1,600 compared to an average of 5,200 across the rest of Europe. French communes represent nearly half of the total number of incorporated communities in Europe! Because of alleged difficulties arising from this large number of lower jurisdictions, a move to encourage cooperation between communes has been im-

\footnotetext{
${ }^{5}$ We do not have data on median income, which is typically used. We use average income instead.
} 
plemented by the French central government since 1992. For this reason, our expenditure figures include contributions to local public goods which are funded by more than one commune.

There exists a clear distribution of responsibilities between the three tiers of local governments. Regions are mainly responsible for economic development and high school buildings and facilities; departments deal with public assistance and buildings and facilities of the colleges (middle schools); while the communes are in charge of public services related to local needs: assistance to individuals, communal roads, municipal police, environment and waste management, water treatment, etc. French communes are governed by municipal councils which are elected by direct universal suffrage. The job of municipal councils is to make decisions about municipal financing and services. For this reason, the determinants of public expenditure fit well into the median voter theory.

In 2004, French GDP amounted to $€ 1,700$ billion. Total public expenditure and local public expenditure respectively represented 54\% and $10.7 \%$ of GDP. Our econometric analysis concerns the commune level. Around $60 \%$ of local public expenditure is made by the communes. Current expenditure accounts for two-thirds to three-fourths of this expenditure. Around $50 \%$ of municipal public revenue comes from taxation and $30 \%$ from central government grants. The remaining $20 \%$ is composed of user fees and borrowing. In addition to the provision of current local public goods, municipalities must finance the depreciation of local public capital. The dependent variable $e$ is thus measured as the sum of current local public good provision by the municipality, depreciation of local public capital, and the contribution of the municipality to local public goods shared with other municipalities.

There are four important local taxes in France: Taxe d'habitation, an occupancy tax; Taxe professionelle, a local business tax; and Taxes foncières sur les propriétés bâties et non-bâties, developed and undeveloped property taxes, respectively. The tax bases of the occupancy and property taxes are calculated from the rental value of housing while the business tax is mainly based on the capital of firms. Local governments are quite unconstrained in setting tax rates; only a few limiting rules exist. In the econometric analysis the total tax base per inhabitant of the municipality $b$ is computed as the sum of the four local tax bases divided by the municipal population, while the tax base of the decisive voter $b_{i}$ is measured by the sum of the occupancy tax base and the property tax bases divided by the population. Variations in the ratio $\frac{b_{i}}{b}$ come mainly from differences in firm location across municipalities. A low ratio indicates that firms bear a high share of local taxes, and that the decisive voter's tax price is low.

There are three kinds of grants from the central government. Dotation globale de fonctionnement (DGF) is lump-sum and partly computed such that it reduces fiscal inequalities among local jurisdictions. It represents more than $20 \%$ of total local revenues for communes. Dotation générale de décentralisation (DGD) is designed to compensate the transfer of responsibilities to the sub-national governments due to the decentralization process. The DGD and the DGF are adjusted upwards annually and are not earmarked transfers. The Dotation d'équipement is designed to help communes finance capital purchases. In our econometric analysis, our variable for grants from the central government, $s$, is measured as the sum of these three grants divided by the population. Table 1 gives definitions of all the variables used in the econometric analysis and Table 2 provides summary statistics. The data come mostly from the Direction générale des collectivités locales of the French Ministry of interior. 
Table 1 Variable definition

\begin{tabular}{|c|c|}
\hline Symbol & Definition \\
\hline$N$ & Municipal population. \\
\hline$e=\frac{E}{N}$ & $\begin{array}{l}\text { Per capita expenditures of local public services (wages of local civil servants, provisions for } \\
\text { depreciation, consumption of other inputs). This variable takes account of both strictly munic- } \\
\text { ipal costs and contributions to cross-municipality public goods. }\end{array}$ \\
\hline$b_{i}$ & $\begin{array}{l}\text { Tax base of the decisive voter which is measured by the sum of the property taxes and occu- } \\
\text { pancy tax bases divided by the municipal population. }\end{array}$ \\
\hline$b$ & $\begin{array}{l}\text { Total tax base per inhabitant (based upon property taxes, local business tax, and occupancy tax } \\
\text { bases). }\end{array}$ \\
\hline$y=\frac{Y}{N}$ & Total household wage and non-wage income in the municipality divided by municipality size. \\
\hline$s=\frac{S}{N}$ & $\begin{array}{l}\text { Grants received by the municipality (the sum of the three main types of central government } \\
\text { grants to the communes) per inhabitant. }\end{array}$ \\
\hline SUR & Surface area of the municipality. \\
\hline ALT & Average altitude of the municipality. \\
\hline$\underline{D_{g}}$ & $=1$ if the municipality belongs to an inter-municipal co-operation structure, 0 otherwise. \\
\hline
\end{tabular}

Small letters generally indicate that the variable is measured in per-capita terms. See Sect. 4 for a detailed description of the tax base

Table 2 Summary statistics (36,000 observations)

\begin{tabular}{lc}
\hline Variables & Mean \\
\hline $\ln (e)$ & 7.9800171 \\
Surface & 1487.1401 \\
Altitude & 305.53586 \\
$\ln (N)$ & 6.0711364 \\
$\ln \left(b_{i} / b\right)$ & -1.1512922 \\
$\ln \left(y_{i}\right)$ & 10.283154 \\
$\ln (s)$ & 6.527747 \\
$D_{g}$ & 0.04088355 \\
\hline
\end{tabular}

\section{Results}

We begin by describing the key variables that we use in our study. Figures 1 to 3 provide the non-parametric density estimates of $\ln (e), N$, and $\ln (N)$. Figures 4 and 5 show the simple bivariate, non-parametric regressions of $\ln (e)$ against $N$ and $\ln (e)$ against $\ln (N)$. The graphs include $95 \%$ (pointwise) confidence intervals.

The first three columns of Table 3 provide the parametric estimates of $\Phi$ and $\Omega$ from (11), (12), and (13). The last column gives the estimates of $\Phi$ from the semi-parametric specification (14). The estimates of $\Phi$ are stable across specifications and unaffected by the choice of congestion elasticity function. Table 4 gives the estimates of demand elasticities and congestion function parameters for the parametric specification and the different formulations of the congestion function. The results are consistent with the theory of demand (see the Appendix for a presentation of these results). 


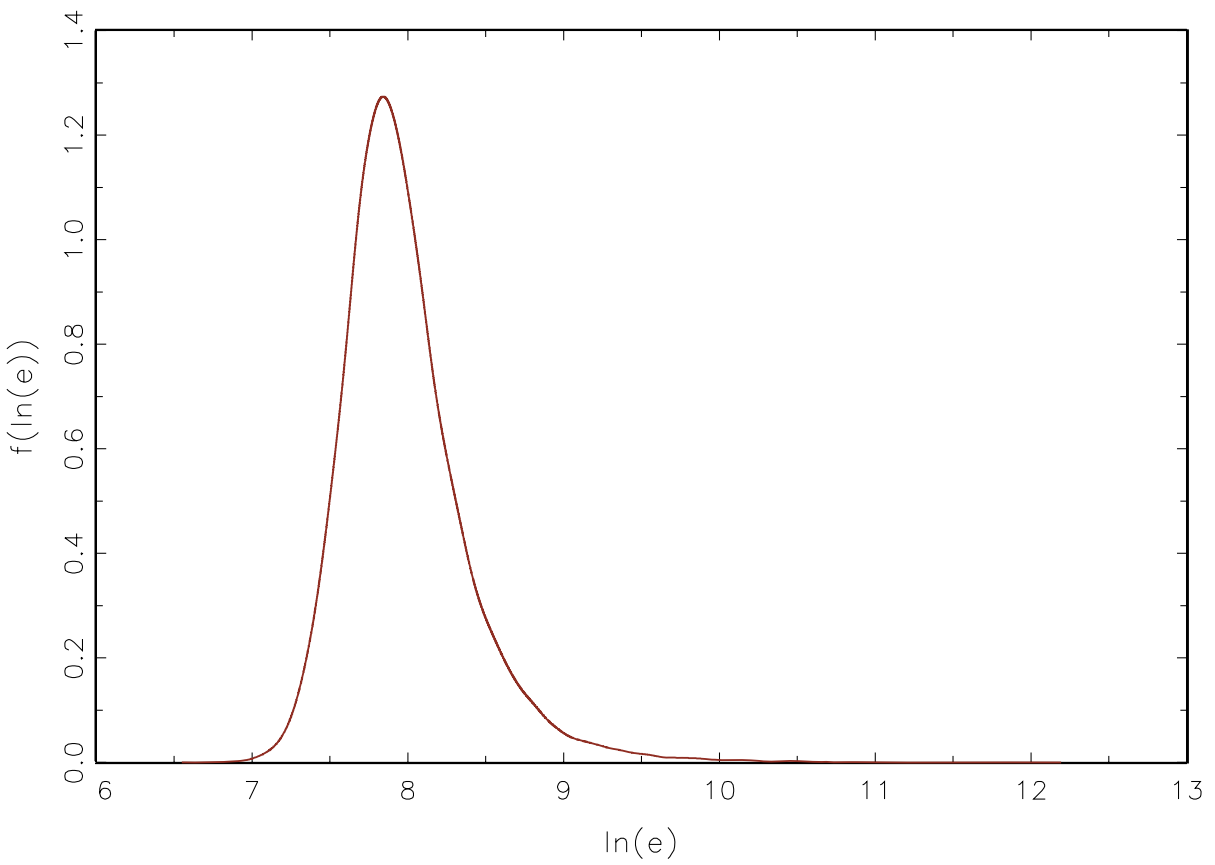

Fig. 1 Non-parametric density estimate of $\ln (e)$

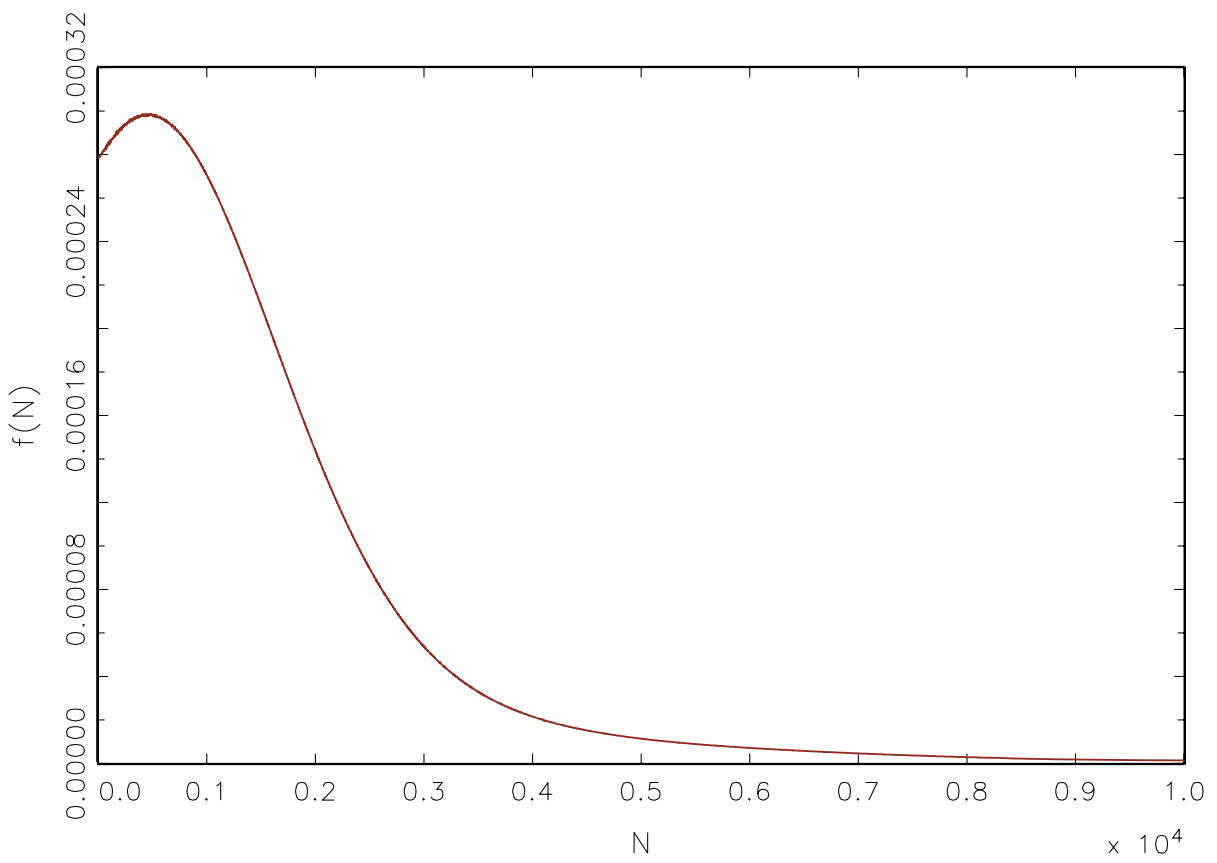

Fig. 2 Non-parametric density estimate of $N$ 


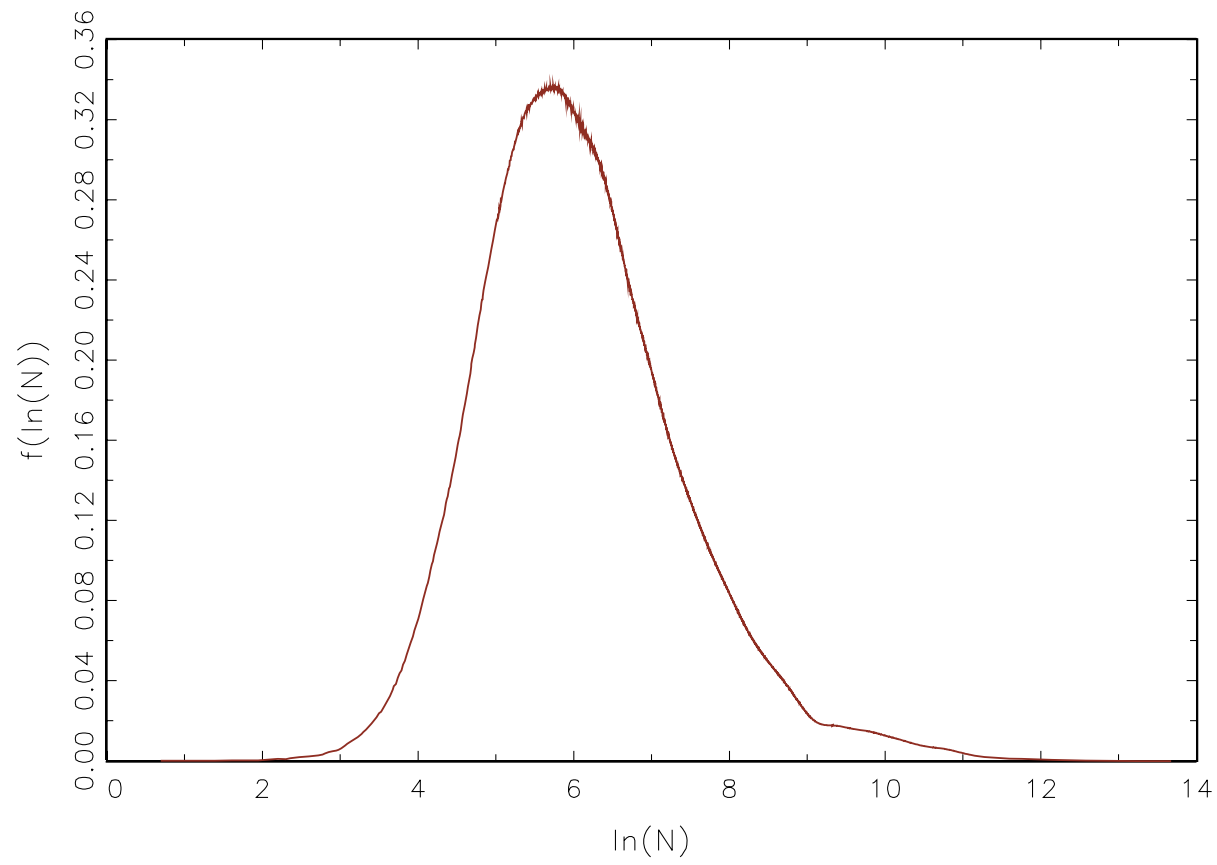

Fig. 3 Non-parametric density estimate of $\ln (N)$

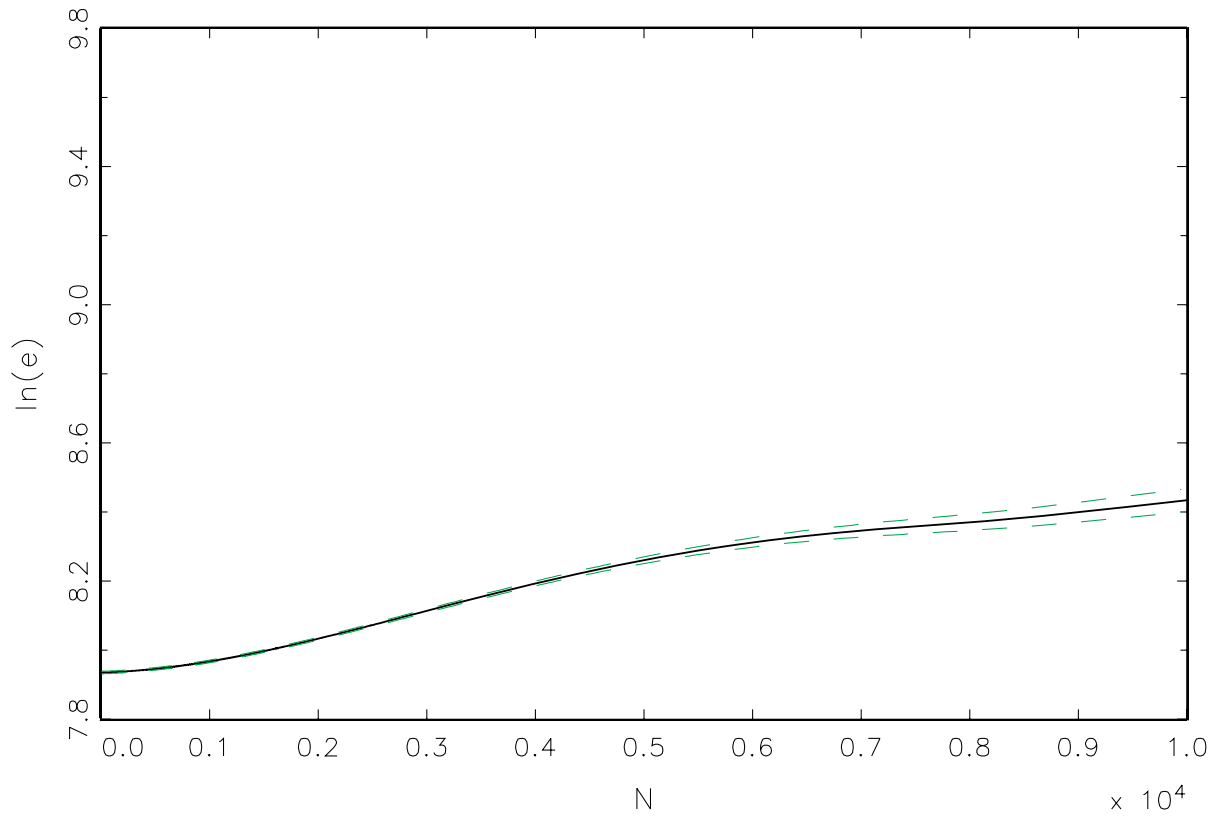

Fig. 4 Non-parametric regression of $\ln (e)$ vs. $N$. Fitted values from simple bivariate regression 


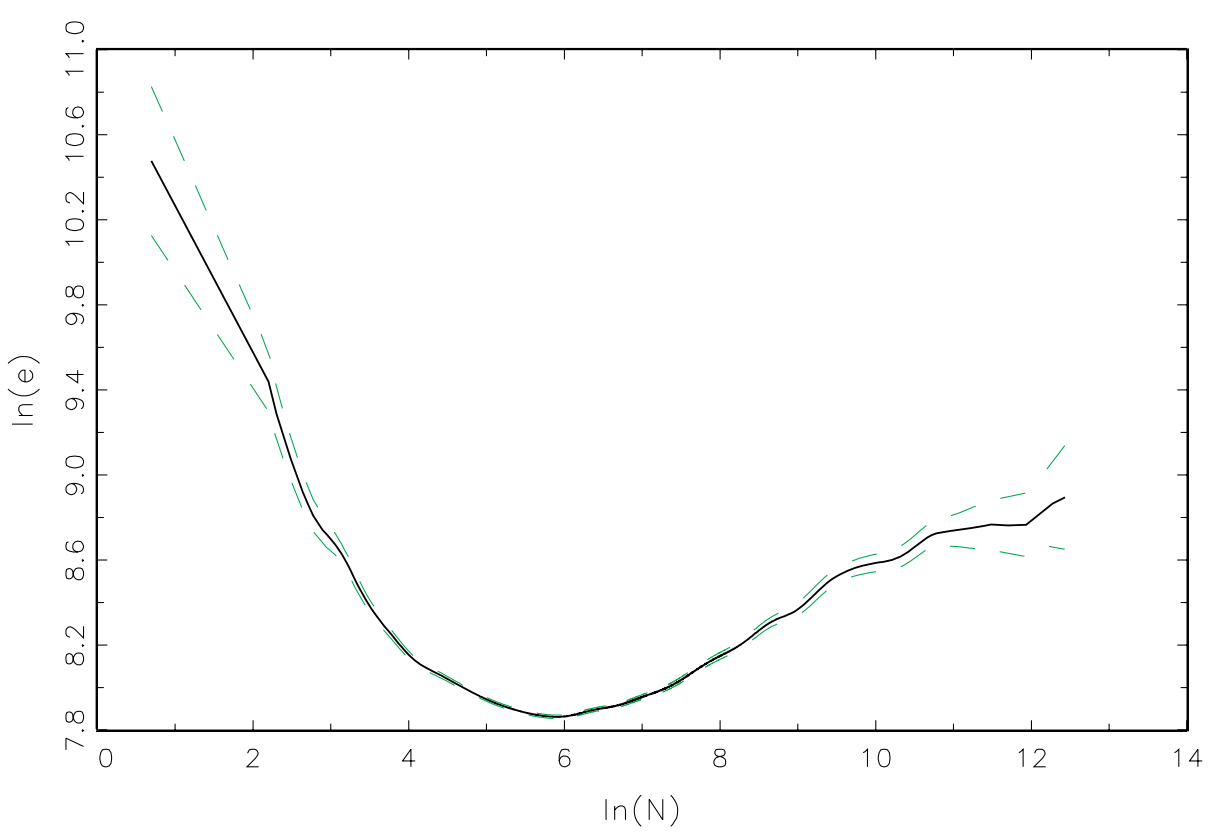

Fig. 5 Non-parametric regression of $\ln (e)$ vs. $\ln (N)$. Fitted values from simple bivariate regression

Figure 6a provides the estimate of $m(\ln (N))$ from the semi-parametric specification. Note that the tail behavior is driven by a very small number of observations and the confidence intervals in the tails are extremely wide. We would caution readers not to draw any inference from the extreme regions of the independent variable. Figure $6 \mathrm{~b}$ provides the range of $m(\ln (N))$ for which the confidence interval is very tight. (We don't graph the confidence intervals because they are nearly indistinguishable from the line-recall that we have over 36,000 observations.)

We compare the responsiveness of the three parametric specifications against the semiparametric specification. We graph the fitted values of $\ln (e)$ against $\ln (N)$ for each specification. In each case, we calculate the fitted values at the means of the independent variables (excluding $N$ ) and allow $N$ to vary while holding the other variables constant. For the semiparametric case, the graph is the non-parametric version of the conditional mean function, which would be a straight line in a linear, parametric specification. Whereas in the linear case, the response is constant ("beta"), here the "beta" varies with $\ln (N)$.

Figure 7 shows all of the parametric and non-parametric specifications together. We can see that the various parametric specifications are all affected by observations in the upperright hand tail of the distribution of commune population sizes and that, due to this, all fail to capture the main U-shaped relationship between log per capita public expenditure and $\log$ population which is captured by the semi-parametric regressions. ${ }^{6}$ The U-shaped relationship is located in the center of the distribution of commune population size, where a

\footnotetext{
${ }^{6}$ We were concerned that this result may be driven by particularly influential observations on the large cities in France and we re-estimated the model, dropping the five largest cities. The results are almost completely unchanged and the failure of the parametric specifications to capture the relationship is robust to dropping these large cities.
} 
Table 3 Estimates of $\Phi$ and $\Omega$

\begin{tabular}{|c|c|c|c|c|}
\hline \multirow[t]{2}{*}{ Variables } & \multicolumn{3}{|l|}{ Parametric estimations } & \multirow{2}{*}{$\begin{array}{l}\text { Semi-parametric } \\
\text { estimation } \\
\text { coefficient } \\
\text { (|t } t \text {-valuel) }\end{array}$} \\
\hline & $\begin{array}{l}\text { Borcherding-Deacon } \\
\text { coefficient } \\
\text { (lt-valuel) }\end{array}$ & $\begin{array}{l}\text { Camaraderie } \\
\text { coefficient } \\
\text { ( } t \text {-valuel) }\end{array}$ & $\begin{array}{l}\text { Flexible } \\
\text { coefficient } \\
\text { (|t-valuel) }\end{array}$ & \\
\hline Constant & $\begin{array}{l}3.32 \\
(93)\end{array}$ & $\begin{array}{l}3.38 \\
(94)\end{array}$ & $\begin{array}{l}3.54 \\
(96)\end{array}$ & $\bullet$ \\
\hline $\ln (\mathrm{SUR})$ & $\begin{array}{l}0.0839 \\
(45)\end{array}$ & $\begin{array}{l}0.0846 \\
(46)\end{array}$ & $\begin{array}{l}0.0883 \\
(48)\end{array}$ & $\begin{array}{l}0.0886 \\
(48)\end{array}$ \\
\hline $\ln (\mathrm{ALT})$ & $\begin{array}{l}0.0341 \\
(23)\end{array}$ & $\begin{array}{l}0.0338 \\
(23)\end{array}$ & $\begin{array}{l}0.0332 \\
(23)\end{array}$ & $\begin{array}{l}0.0311 \\
(21)\end{array}$ \\
\hline $\ln \left(\frac{b_{i}}{b}\right)$ & $\begin{array}{l}-0.138 \\
(45)\end{array}$ & $\begin{array}{l}-0.138 \\
(45)\end{array}$ & $\begin{array}{l}-0.135 \\
(44)\end{array}$ & $\begin{array}{l}-0.129 \\
(43)\end{array}$ \\
\hline $\ln (s)$ & $\begin{array}{l}0.411 \\
(209)\end{array}$ & $\begin{array}{l}0.410 \\
(207)\end{array}$ & $\begin{array}{l}0.405 \\
(205)\end{array}$ & $\begin{array}{l}0.395 \\
(201)\end{array}$ \\
\hline $\ln \left(y_{i}\right)$ & $\begin{array}{l}0.0707 \\
(23)\end{array}$ & $\begin{array}{l}0.0681 \\
(22)\end{array}$ & $\begin{array}{l}0.0611 \\
(20)\end{array}$ & $\begin{array}{l}-0.0182 \\
(4)\end{array}$ \\
\hline$D_{g}$ & $\begin{array}{l}0.226 \\
(35)\end{array}$ & $\begin{array}{l}0.224 \\
(35)\end{array}$ & $\begin{array}{l}0.221 \\
(34)\end{array}$ & $\begin{array}{l}0.210 \\
(33)\end{array}$ \\
\hline $\ln (N)$ & $\begin{array}{l}0.052 \\
(45)\end{array}$ & $\begin{array}{l}0.0472 \\
(38)\end{array}$ & $\begin{array}{l}0.0328 \\
(23)\end{array}$ & \\
\hline$N$ & $\bullet$ & $\begin{array}{l}0.0162 \\
(10)\end{array}$ & $\begin{array}{l}0.0926 \\
(22)\end{array}$ & \\
\hline$N^{2}$ & $\bullet$ & $\bullet$ & $\begin{array}{l}-0.00438 \\
(17)\end{array}$ & \\
\hline$N^{3}$ & $\bullet$ & $\bullet$ & $\begin{array}{l}0.0000385 \\
(15)\end{array}$ & \\
\hline
\end{tabular}

$N$ is scaled by $10,000, N^{2}$ is scaled by $10,000^{2}$, and $N^{3}$ is scaled by $10,000^{3}$. The constant is not identified in the semi-parametric specification without further assumptions

substantial number of communes are located, and is an essential feature that the parametric specification completely fails to capture.

In the Borcherding-Deacon, Camaraderie, and Flexible specifications, local public expenditure per capita is an increasing monotonic function of commune population size. The story behind this result is straightforward. If local public goods appear to be highly congestible $(\eta<-1)$, an increase in commune population size generates a rise in individual tax price as stated by (7). If the demand for quality of local public goods is inelastic to tax price changes $(\alpha<-1)$, as we consistently find in all specifications (Table 4$)$, this tax price increase generates a small reduction in the public good quantities provided by the municipality and then a rise in per capita local public expenditure. The parametric estimates suggest that local public goods are highly congestible whatever the population size of the communes.

The non-parametric estimates give a radically different story. The U-shaped curve suggests that local public goods are less congestible in small communes than they are in more populated jurisdictions. For communes with few inhabitants, a population increase generates a lower tax price, (because of $\eta>-1$ ), and a small increase in local public goods provided 
Table 4 Estimates of demand elasticities and congestion function parameters

\begin{tabular}{llll}
\hline & $\begin{array}{l}\text { Borcherding- } \\
\text { Deacon } \\
\text { coefficient } \\
(\mid t \text {-valuel) }\end{array}$ & $\begin{array}{l}\text { Camaraderie } \\
\text { coefficient } \\
(\mid t \text {-valuel })\end{array}$ & $\begin{array}{l}\text { Flexible } \\
\text { coefficient } \\
(\mid t \text {-valuel) }\end{array}$ \\
\hline $\begin{array}{lll}\text { Demand elasticities } \\
\alpha\end{array}$ & -0.550 & -0.547 & -0.540 \\
$\beta_{y}$ & $(160)$ & $(159)$ & $(157)$ \\
$\beta_{S}$ & 0.0707 & 0.0681 & 0.0611 \\
Congestion function & $(23)$ & $(22)$ & $(20)$ \\
parameters & 0.411 & 0.410 & 0.405 \\
$\gamma_{0}$ & $(209)$ & $(207)$ & $(205)$ \\
$\gamma_{1}$ & & & -1.071 \\
$\gamma_{2}$ & -1.116 & -1.104 & $(311)$ \\
$\gamma_{3}$ & $(400)$ & $(375)$ & -0.202 \\
& $\bullet$ & -0.036 & $(22)$ \\
\hline
\end{tabular}

$N$ is scaled by $10,000, N^{2}$ is scaled by $10,000^{2}$, and $N^{3}$ is scaled by $10,000^{3}$

(because of $\alpha<-1$ ) which yield a reduction in local public expenditure per person. Per capita local public expenditures reach a minimum for a population size of around 400 inhabitants. Around half of the 36,000 French communes have populations of less than 400 inhabitants as depicted in Fig. 7. At this threshold the congestion elasticity is equal to -1 . Above this threshold we find the same result as the parametric specification, that is highly congestible public goods $(\eta<-1)$, and per capita public expenditures increasing with population size.

\section{Discussion and conclusions}

Using semi-parametric regression techniques, we find scale economies in the provision of local public goods for small municipalities. This result is in contrast to the parametric literature, which concludes that local public goods are not different from private goods. Theory predicts a U-shaped relationship between population size and per capita public expenditure. We find, in contrast to previous studies, that this relationship does appear to hold empirically. Previous studies have suggested that congestion in the consumption of local public goods seems to be so high that it outweighs any tax-sharing advantages. We find that this is not true for small local authorities.

In France, where there are approximately 18,000 communities with 400 or less members, the results are quite relevant. For the United States, there are very few incorporated 


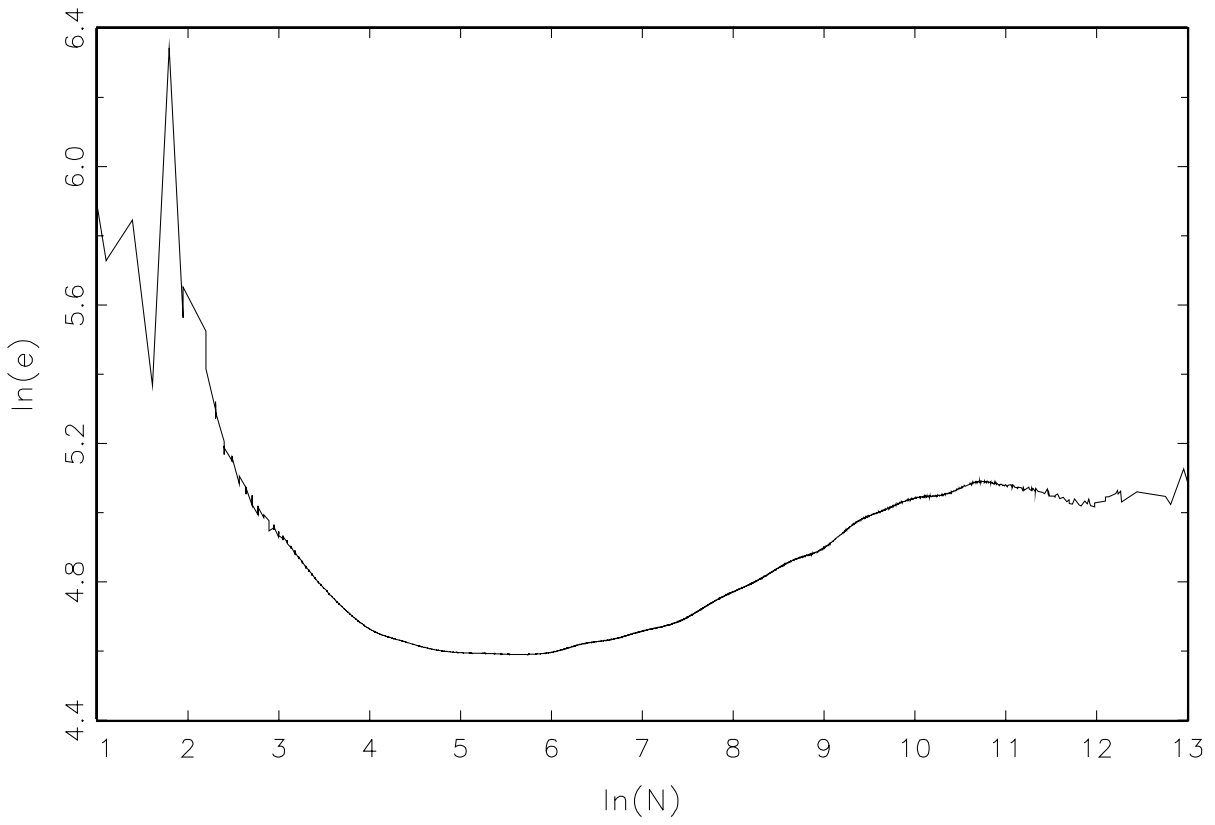

Fig. 6a Semi-parametric regression of $\ln (e)$ vs. $\ln (N)$. Estimate of $m(\ln (N))$

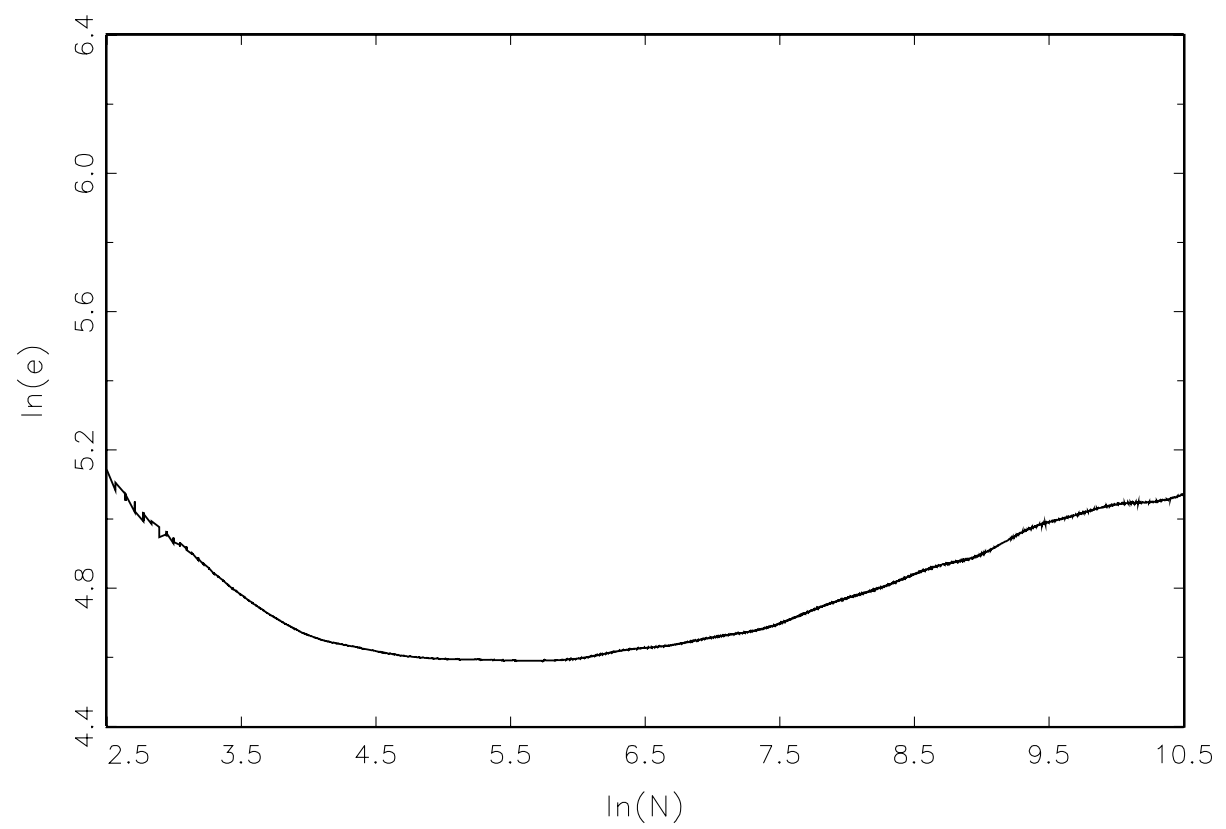

Fig. 6b Semi-parametric regression of $\ln (e)$ vs. $\ln (N)$. Estimate of $m(\ln (N))$ 


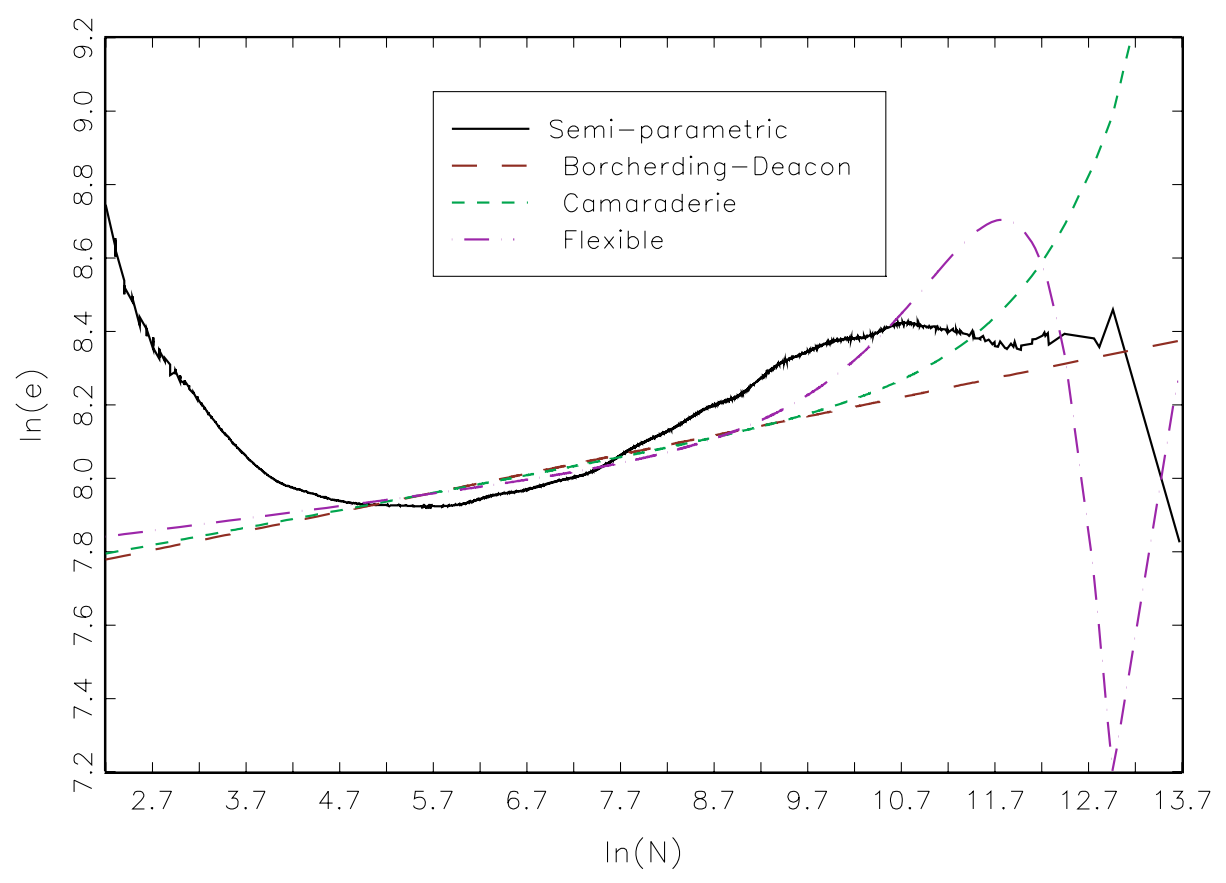

Fig. 7 Semi-parametric compared to all parametric specifications

communities with such small populations and, in that case, local public goods may behave no differently than private goods due to congestion. Our results suggest that the ' $\mathrm{U}$ shaped' relationship is not particularly relevant in this case. A semi-parametric approach may still be informative, however. Looking at Fig. 7, all of the parametric specifications under-predict the amount of per-person public expenditure for communities in the range of 2,000 to 150,000 inhabitants. This under-prediction is sometimes quite severe, up to $40 \%$. That none of the parametric specifications fit the French data well is an interesting result and suggests that a semi-parametric approach might be warranted in other cases.

We attribute the relationship between per-person expenditure and population size to the joint action of congestion costs and tax sharing. Our strategy for separating these two effects is to make the assumption that unit costs of production are constant across municipalities of different sizes, after controlling for surface area and altitude. Given France's centralized wage structure we think this is a reasonable assumption, but we do remind readers that the congestion interpretation is dependent upon it.

The paper makes a contribution to local public economics by bridging an existing gap in the literature between theory and empirical observation. It also provides a compelling example of the advantages of semi-parametric estimation and its ability to uncover features of the data which are hidden by standard parametric techniques.

Acknowledgements We thank Geoffrey Brennan and Richard Cornes for their comments on the paper. We have benefited from the comments of seminar participants at the 2006 Australasian Econometric Society Meetings, the Australian National University and the University of Rennes I. We are grateful to William F. Shughart II and two referees of this journal for suggestions and help. 


\section{Appendix: estimation of demand elasticities and congestion function parameters from parametric specifications}

We specify the following demand function for the total quality, $q$, of public goods consumed by a community

$$
\begin{aligned}
q & =k c_{i}^{\alpha} y_{i}^{\beta_{y}}\left(s \frac{b_{i}}{b}\right)^{\beta_{s}} \\
& =k\left[\frac{b_{i}}{b} \frac{p}{N g(N)}\right]^{\alpha} y_{i}^{\beta_{y}}\left(s \frac{b_{i}}{b}\right)^{\beta_{s}},
\end{aligned}
$$

where the subscript $i$ refers to the decisive voter. The tax price for the decisive voter is the term in square brackets, $\alpha$ denotes the price elasticity, $\beta_{y}$ the income elasticity, and $\beta_{s}$ the grant elasticity.

Using $q=g(N) Z$ and re-writing this in terms of per-person expenditures, some rearrangement provides

$$
e=k^{*}\left(\frac{b_{i}}{b}\right)^{\alpha+\beta_{s}} s^{\beta_{s}} y_{i}^{\beta_{y}}[N g(N)]^{-(\alpha+1)},
$$

where $k^{*}=k p^{\alpha+1}$. From (16), taking logs, we have

$$
\begin{aligned}
\ln (e)= & k^{*}+\left(\alpha+\beta_{s}\right) \ln \left(\frac{b_{i}}{b}\right)+\beta_{s} \ln (s)+\beta_{y} \ln \left(y_{i}\right) \\
& -(\alpha+1) \ln (N)-(\alpha+1) \ln [g(N)] .
\end{aligned}
$$

Plugging the three specifications of the congestion function $g(N)$ in expression (17) gives:

1. Borcherding and Deacon $g(N)=N^{\gamma_{0}}$ :

$$
\begin{aligned}
\ln (e)= & k^{*}+\left(\alpha+\beta_{s}\right) \ln \left(\frac{b_{i}}{b}\right)+\beta_{y} \ln \left(y_{i}\right)+\beta_{s} \ln (s) \\
& -(\alpha+1)\left(\gamma_{0}+1\right) \ln (N) .
\end{aligned}
$$

2. Camaraderie $g(N)=N^{\gamma_{0}} e^{N \gamma_{1}}$ :

$$
\begin{aligned}
\ln (e)= & k^{*}+\left(\alpha+\beta_{s}\right) \ln \left(\frac{b_{i}}{b}\right)+\beta_{y} \ln \left(y_{i}\right)+\beta_{s} \ln (s) \\
& -(\alpha+1)\left(\gamma_{0}+1\right) \ln (N)-(\alpha+1) \gamma_{1} N .
\end{aligned}
$$

3. Flexible $g(N)=N^{\gamma_{0}} e^{\gamma_{1} N+\gamma_{2} N^{2}+\gamma_{3} N^{3}}$ :

$$
\begin{aligned}
\ln (e)= & k^{*}+\left(\alpha+\beta_{s}\right) \ln \left(\frac{b_{i}}{b}\right)+\beta_{y} \ln \left(y_{i}\right)+\beta_{s} \ln (s) \\
& -(\alpha+1)\left(\gamma_{0}+1\right) \ln (N)-(\alpha+1) \gamma_{1} N-(\alpha+1) \gamma_{2} N^{2}-(\alpha+1) \gamma_{3} N^{3} .
\end{aligned}
$$


The estimation results are given in Table 4. Elasticity estimates are close to what is generally found by studies in the Bergstrom-Goodman tradition. Price elasticity is around -0.5 which suggests that demand for local public goods is price-inelastic. Income elasticity is positive but of a low value, around 0.07 , indicating that local public goods are normal goods, but whose consumption is not very sensitive to income changes. Finally grant elasticity is found to be positive, equal to 0.4 , which is consistent with the microeconomic grant theory. As for congestion function parameters, $\gamma_{0}$ is less than -1 , which might be viewed as local public goods being quasi-private goods. Moreover since $\gamma_{0}$ and $\gamma_{1}$ are both negative, marginal congestion decreases with population (for a more detailed analysis of the parametric approach, see Guengant et al. 2002).

\section{References}

Bergstrom, T. C., \& Goodman, R. P. (1973). Private demand for public goods. American Economic Review, 63, 286-296.

Borcherding, T. E., \& Deacon, R. T. (1972). The demand of services of non-federal governments. American Economic Review, 62, 891-901.

Buchanan, J. M. (1965). An economic theory of clubs. Economica, 32, 1-14.

Cornes, R. C., \& Sandler, T. (1996). The theory of externalities, public goods and club goods (2nd edn.). Cambridge: Cambridge University Press.

Gonzalez, R., Means, T. S., \& Mehay, S. (1993). Empirical tests of the Samuelsonian publicness parameter: has the right hypothesis been tested? Public Choice, 77, 523-534.

Guengant, A., Josselin, J. M., \& Rocaboy, Y. (2002). Effects of club size in the provision of public goods: network and congestion effects in the case of the French municipalities. Papers in Regional Science, 81, 443-460.

Holcombe, R. G., \& Sobel, R. S. (1995). Empirical evidence on the publicness of State legislative activities. Public Choice, 83, 47-58.

Hudson, J., \& Jones, P. R. (2005). "Public goods": an exercise in calibration. Public Choice, 124, 267-282.

McMillan, M. C., Wilson, R. W., \& Arthur, L. (1981). The publicness of local public goods: Evidence from Ontario municipalities. Canadian Journal of Economics, 14, 596-608.

Oates, W. (1988). On the measurement of congestion in the provision of local public goods. Journal of Urban Economics, 24, 85-94.

Reiter, M., \& Weichenrieder, A. (1997). Are public goods public: a critical survey of the demand estimates for local public services. Finanzarchiv, 54, 374-408.

Reiter, M., \& Weichenrieder, A. (1999). Public goods, club goods and the measurement of crowding. Journal of Urban Economics, 46, 69-79.

Turnbull, G. K., \& Mitias, P. M. (1995). Which median voter? Southern Economic Journal, 62, 183-191.

Turnbull, G. K., \& Mitias, P. M. (1999). The median voter model across levels of government. Public Choice, 99, 119-138. 